\title{
The COVID-19 pandemic: resilient organisational response to a low-chance, high-impact event
}

\author{
McKenzie Lloyd-Smith
}

Faculty of Management, Cass Business School, London, UK

\section{Correspondence to}

McKenzie Lloyd-Smith, Cass Business School, London EC1Y 8TZ, UK;

mckenzie.lloyd-smith@cass. city.ac.uk

Received 1 April 2020 Revised 20 April 2020 Accepted 23 April 2020 Published Online First 18 May 2020

\section{ABSTRACT}

The global healthcare sector is currently in the midst of the COVID-19 pandemic, a 'low-chance, high-impact' event which will require healthcare systems, and the organisations within them, to maintain organisational resilience in order to respond effectively. However, contrary to the instinctive reaction to tighten control, the quality of response depends on healthcare systems' capacity to loosen control and, subsequently, enhance improvisation. Three factors critical to enhancing an organisation's capacity for improvisation are highlighted; increasing autonomy, maintaining structure and creating a shared understanding. By drawing on the case of Christchurch Hospital's response to a major earthquake, this paper demonstrates the vital role that improvisation can play within a clinical setting, when responding to a low-chance, high-impact event.

\section{INTRODUCTION}

At the time of writing, the cumulative global number of COVID-19 cases sits at 1595 350, a growth of over 85000 cases in a single day-the second largest yet-with no sign of growth abating soon. ${ }^{1}$ Rather than routine emergencies, the global healthcare sector is currently dealing with a 'lowchance, high-impact' event. ${ }^{2}$ One which creates an urgent threat to social and life-sustaining systems, creates deep uncertainty and requires international governmental intervention. ${ }^{2}$ In order to respond effectively, healthcare systems and organisations within them need to 'proactively adapt to and recover from' this pandemic, which falls outside the range of expected disturbances; we call this 'organisational resilience'. However, in low-chance, high-impact events, evidence suggests that plans often fail, communications falter and commandand-control systems do not work as expected. ${ }^{24}$ Contrary to the natural reaction to tighten control in the face of such events, organisational resilience often depends on the ability of an organisation's leadership to loosen control which, ${ }^{5}{ }^{6}$ in turn, increases the capacity for improvisation. ${ }^{7}$

When responding to routine emergencies, rapid response benefits from hierarchical decision-making and formal coordination with clear lines of authority and command. ${ }^{8}$ In emergency medical care, as with firefighting and police response, these organisational features are pre-existing and well used which allows for seamless rapid response to commonly faced situations. ${ }^{8}$ However, when low-chance, high-impact events occur, conditions change from routine to novel and represent a fundamental shift to an organisation's environment. ${ }^{9}$ In such circumstances, the context in which decisions are being made and action unfolds is often changing, unexpected and unforeseen. Thus, response requires flexibility, on-the-spot decision-making and informal coordination. ${ }^{10}$ As conditions shift from routine to novel, such as those being experienced within healthcare systems responding to COVID19 , rigidly clinging onto pre-existing routines and control structures is likely to undermine resilience and backfire with tragic consequences. ${ }^{9}$ Instead, organisations are required to creatively use existing resources, structures and processes, and enable their recombination to extend the range of alternative solutions to problems arising from the event. ${ }^{9}$

Rather than attempting to provide a comprehensive review of resilience or improvisation, ${ }^{3}{ }^{11}$ the focus of this paper is on highlighting the role that improvisation plays within resilience. I start by highlighting key findings regarding an organisation's capacity for improvisation during the handling of low-chance, high-impact events. By drawing on the case of Christchurch Hospital's response to a major earthquake, I show the vital role that improvisation can play within a clinical setting facing a novel and deeply uncertain situation. I subsequently review three enabling factors for increasing an organisation's capacity for improvisation: increasing autonomy; maintaining structure, and; creating a shared understanding. I conclude with a brief discussion of the risks and challenges associated with improvisation.

\section{ORGANISATIONAL IMPROVISATION: CREATING ORDER FROM CHAOS}

Regardless of how well prepared an organisation is, it can never predict all potentialities, due to the cognitive limitations which stop us from anticipating all possible situations and consequences. ${ }^{12}$ It would be impossible to anticipate and prepare for every event in advance and, therefore, unexpected situations will inevitably occur. ${ }^{13}$ During such situations, including those induced by low-chance, high-impact events, the optimal deployment of resources is made difficult, if not impossible, as little or no time is available to allow for the conventional sequence of planning, formulating and implementing. ${ }^{14}$ Organisational improvisation, defined as 'the conception of action as it unfolds, by an organisation and/or its members, drawing on available material, cognitive, affective and social resources', occurs when this conventional sequence is replaced by cognition and action occurring simultaneously. ${ }^{15}$

Improvisation is a creative act, at the intersection of intuition and spontaneity. ${ }^{15}$ Individuals who successfully improvise remain creative under pressure by pulling order out of chaotic conditions, so that, when a novel situation occurs which renders
To cite: Lloyd-Smith MK 112 
existing operating procedures and control structures inadequate, the improvisor is able to replace traditional order with an improvised one. ${ }^{16}$ If resilience is embodied in making do with the resources you have to recover from larger than expected disturbances, which are neither fully controlled nor completely understood, ${ }^{17}$ improvisation is the spontaneous and creative act of finding solutions. ${ }^{12}$ In contrast, refusing to make decisions in the absence of complete and accurate information, or attempting to optimise resources before deployment will inevitably lead to avoidable failure. ${ }^{2}$ This ability to creatively respond within uncertain conditions makes improvisation during a low-chance, high-impact event not only possible, but critically important for a resilient organisational response. ${ }^{12}$

Take the example of New Zealand's Christchurch Hospital which, on 22 February 2011, was struck by a magnitude 6.3 earthquake, causing damage which led to a $16 \%$ loss of total in-patient capacity. ${ }^{18}$ The acute medical wards were not structurally damaged but their function was compromised by water leaks and loss of utilities, including communications, water and electricity. ${ }^{19}$ Ongoing seismic activity meant staff were unable to stand unsupported, ${ }^{18}{ }^{20}$ yet the acute ward staff maintained their responsibility of providing patient care, while attempting to make the immediate environment safe by identifying and reporting damage. ${ }^{18}$ Ground tremors continued for days and utilities failed for weeks. ${ }^{19}$ In this low-chance, high-impact event, had the clinical team waited for the reinstatement of traditional order, or complete information about the situation-thereby allowing them to follow their standard operating procedurespatients would have received delayed care, potentially resulting in suffering or death. ${ }^{21}$ Instead, the team abandoned traditional order, rapidly constituted a new situation, and improvised solutions to ensure the safety and uninterrupted care of patients.

Subsequent to the immediate response, a decision was made to evacuate patients and permanently close the three acute medical wards. ${ }^{18}$ Within 1 week of the earthquake, a new ward was to be created in a nearby hospital and patients relocated. The hospital to which the acute wards were to be relocated did not have an acute-admitting facility nor emergency department services. ${ }^{22}$ This meant that the team faced complex problems while establishing a fully viable acute ward, including a lack of proper infrastructure and the inability to maintain existing operational procedures, while the split of acute services across two hospitals posed additional risk to patient safety by potentially limiting continuity of care and disrupting the existing model of care delivery. ${ }^{18}$ To sustain uninterrupted acute care the team adopted creative and critical thinking, developing workarounds to overcome hindrances, ${ }^{23}$ and gradually incorporated these workarounds into daily operations. ${ }^{18}$ Infrastructure was quickly installed, new operational procedures established, policies modified, technology adopted and a new model of care delivery implemented almost immediately. The acute medical team had no training in responding to this type of low-chance, highimpact event, yet rapidly responded to the situation without the benefit of prior planning. ${ }^{18}$

The present challenge for clinical leaders in the midst of the COVID-19 pandemic is to loosen control, in order to increase organisational capacity for improvisation. However, this loosening of control is counterintuitive within the healthcare context, in which resilience is traditionally synonymous with enforcing compliance, increasing bureaucratic constraints and reducing procedural deviations. ${ }^{24} 25$ Evidence shows, however, that improvisation neither requires nor benefits from anarchical organisation. ${ }^{26}$ Instead, research reveals that improvisations are already successfully used within clinical settings, especially those characterised by uncertainty, such as trauma units. ${ }^{21}$ This paper subsequently introduces three factors which are critical to enhancing an organisation's capacity for improvisation; autonomy, structure and shared understanding. The role played by each factor is analysed within the case of Christchurch Hospital to understand its importance in responding to a novel and deeply uncertain situation.

\section{ENABLING IMPROVISATION: INCREASING AUTONOMY}

While tight structuring, hierarchical decision-making and formal coordination are important for rapid organising and efficient functioning in routine conditions, ${ }^{8}$ these become increasingly vulnerable as conditions shift from routine to uncertain, often becoming entirely inappropriate in novel conditions. ${ }^{27}$ The first phase of a low-chance, high-impact event is inevitably marked by novelty, caused by a lack of information, communication and coordination. $^{2}$ In such circumstances, it would be impossible to control every action made at the operational level, such as front-line clinicians, ${ }^{5}$ and attempts by leadership to do so would quickly result in a bottleneck in decision-making, slowing down response and impeding both flexibility and local initiative. ${ }^{5}$ In addition, those in front-line roles are likely to know more about the current situation than those within more centralised roles, allowing them to take more appropriate action based on immediate needs. ${ }^{28}$ The marginalisation of front-line staff during a low-chance, high-impact event leads to an inefficient response and a suboptimal outcome. ${ }^{28}$ In contrast, teams and organisations which consistently operate error-free in highly uncertain conditions display the tendency to push decision-making to the frontline, ${ }^{8} 29$ to those with the most expertise and/or specific knowledge about the situation, regardless of rank or seniority. ${ }^{17}$ By increasing autonomy and allowing decision rights to migrate, leaders encourage improvisation by enabling front-line staff to act spontaneously, guided by intuition, which increases the likelihood that challenges will be overcome. ${ }^{15} 30$

The migration of authority encourages faster response, and has been shown to be successful in clinical settings. For example, the Loma Linda University Children's Hospital, California, operates a paediatric intensive care unit (PICU) that has been designed around this principle. ${ }^{31}$ Due to the complexity and pace of change occurring within a PICU setting, the unit accommodates the likely scenario that decisions will have to be made without perfect information. Rather than relying on strict protocols and hierarchical decisions regarding patient care, decisions within the PICU are migrated down to the staff with the best knowledge of the situation, regardless of rank or seniority. ${ }^{31} \mathrm{By}$ designing for autonomy, clinical leaders enable flexibility and on-the-spot decision-making by those most informed, allowing front-line staff to deliver patient care more effectively, ${ }^{31}$ and earning the hospital consistently high patient care results. ${ }^{32}$ In the case of Christchurch Hospital, had front-line staff waited for instructions from clinical leaders, rather than acting immediately in the initial response to the earthquake, patients would have received delayed care. By acting autonomously, front-line staff relied on expertise, intuition and specific knowledge of their circumstances which generated faster, more informed decisions and thus a more resilient response. ${ }^{17}$

\section{ENABLING IMPROVISATION: MAINTAINING STRUCTURE}

The second enabling factor for improvisation is the maintenance of a structure with clear lines of communication and coordination. Despite the need for loosened control, improvisation neither requires, nor benefits from, total anarchy. Rather 
than materialising 'out of thin air', ${ }^{26}$ improvisation comes from adjustments to, and recombinations of, already existing resources. ${ }^{9}$ Continuing to maintain some structure provides a 'common frame' around which adjustments can occur. ${ }^{14}$ To ensure autonomy is preserved, this structure may be absent of explicit rules, freeing up individuals to respond as required. But guidelines with a high degree of flexibility support creative adjustments, while helping strike a balance between control and autonomy. ${ }^{33}$ Further, resilient response to low-chance, highimpact events requires collective behaviour rather than solo acts. ${ }^{34}$ Maintaining structure supports collective behaviour by enabling coordination via communication. ${ }^{10}$ Maintaining coordination while increasing autonomy actively enables front-line staff to improvise, by allowing individuals to effectively and continuously integrate their behaviours with others. As a result, an organisation is able to remain stable while becoming exceptionally flexible to the demands of the situation. ${ }^{8}$

Healthcare systems are in the advantageous position of being able to rely on pre-existing role structures, providing front-line staff with an expectation of how their behaviours will integrate with others. ${ }^{35}$ Reflecting on Christchurch Hospital's response to the earthquake, accounts highlight that self-organising behaviour, 'out of the box' thinking and problem-solving occurred between frontline clinical staff attempting to establish a fully viable acute medical ward in less than 1 week. ${ }^{18}$ This rapid, autonomous response was underpinned by a coordination meeting between senior clinicians from different departments and the establishment of a hospital control room. ${ }^{22}$ Members of different medical teams cooperated in a shared decision-making process which acted to coordinate activities based on existing roles, while debrief exercises were used to communicate new protocols and procedures. ${ }^{18}$ By melding the existing role structure with autonomy-enhancing processes, Christchurch Hospital was able to enhance and sustain organisational resilience, enabling their effective response. ${ }^{21}$

\section{ENABLING IMPROVISATION: CREATING A SHARED UNDERSTANDING}

When tasks are complex and organisations large, such as those within healthcare systems, it is difficult for individuals to be fully aware of the interdependencies of their actions. ${ }^{36}$ This is further exacerbated in highly demanding situations, such as low-chance, high-impact events, during which individuals may be unable to maintain holistic awareness of the situation. ${ }^{8}$ However, as we have already established, resilient organisational response requires collective behaviour rather than individual acts. ${ }^{34}$ Therefore, creating a shared understanding of a situation helps teams improvise solutions to problems found within the complex and uncertain conditions produced by such events. ${ }^{8}$

Traditionally created by plans, rules and familiarity, in novel situations a shared understanding is produced through direct information sharing. ${ }^{37}$ The monitoring of activities and frequent updating of progress within groups allows interdependent tasks to be coordinated, ${ }^{21}$ while liaising between groups allows for coordination across an organisation. ${ }^{38}$ This timely sharing of information, supported by a structure, allows individuals to create and sustain a 'big picture' of the situation at any one moment. ${ }^{30}$ While the initial phase of a low-chance, high-impact event is often characterised by failure of communication, ${ }^{24}$ the subsequent establishment of a shared understanding of the situation enables front-line operators to remain sensitive to operations, and aware of how their decisions and actions potentially impact others; ${ }^{39}$ a vital process in uncertain and rapidly changing conditions. ${ }^{10}$ Further, by creating a shared understanding of the situation, individuals become aware of how their efforts fit together with others to achieve the desired outcome. ${ }^{37}$ In contrast, a lack of shared understanding has been shown to produce less effective responses to such events. ${ }^{28}$

In the aftermath of the 2011 earthquake, Christchurch Hospital's communication systems ceased to function due to the main power and backup generators failing. ${ }^{22}$ The hospital received little information about the impact of the earthquake, leaving them unable to predict the number of casualties or when they would arrive. ${ }^{22}$ However, a shared understanding of the situation was quickly enabled by the provision of communication technologies including radiotelephones and mobile phones to key staff, while direct information sharing occurred via a loudspeaker system which communicated updates. ${ }^{22}$ This development of shared understanding was supported by the senior clinician coordination meeting. ${ }^{22}$ By creating a shared understanding of the unfolding situation and facilitating communication throughout the response, Christchurch Hospital's leadership enabled frontline staff to coordinate under novel circumstances, ${ }^{21}$ allowing individuals to improvise solutions to problems and understand how their actions and decisions were embedded within a larger operation. $^{35}$

\section{RESILIENT RESPONSE: SACRIFICING OPTIMISATION}

When responding to low-chance, high-impact events, organisations are forced to cope with novel situations which are likely to be both unexpected and deeply uncertain. ${ }^{2}$ Resilience will be necessary for organisations to cope with, and recover from, such disturbances. ${ }^{9}$ Due to the non-routine nature of such circumstances, existing routines and processes will no longer apply, as unvarying practices cannot handle what they do not anticipate $^{30}$ The rapid response required for handling low-chance, high-impact events forces the conventional sequence of planning, formulating and implementing to be supplanted by the simultaneous occurrence of cognition and action, resulting in organisational improvisation. ${ }^{14}{ }^{15}$ By replacing traditional order with an improvised one, an organisation increases its chances of recovering from a larger than expected disturbance, which is neither fully controlled nor completely understood. ${ }^{5}{ }^{16}$ There is, however, variability in both 'the quality of improvisational action and its suitability under various conditions' and, therefore, the potential negative implications of improvisation are worth acknowledging. ${ }^{15}$

By adopting improvisation, an organisation is unable to centrally control the use of resources, and therefore deploy them optimally; potentially leading to their inefficient or ineffective use. ${ }^{714}$ In addition, improvisations are inherently unpredictable, and one aimed at solving a problem could accidentally escalate it. ${ }^{40}$ This can lead to the creation of a 'spiral of complexity' in which an improvisation to overcome one problem creates another unexpected problem, requiring further improvisation and leading to an escalating lack of control. ${ }^{7}$ Most importantly for a clinical setting, improvisations should only be undertaken, and supported, on the condition that they fit with the organisational goals and are unlikely to cause harm to patients or staff. ${ }^{8}$

Despite the potential disadvantages of enabling improvisation, the alternative is the maintenance of organisational rigidity. During a low-chance, high-impact event, mandating adherence to inflexible protocols, refusing to make or allow decisions in the absence of complete information, or attempting to optimise resources before deployment, will inevitably lead to avoidable failure. $^{5}$ 


\section{CONCLUSION: RESILIENT ORGANISATIONAL RESPONSE TO THE COVID-19 PANDEMIC}

The COVID-19 pandemic can be considered a low-chance, high-impact event. ${ }^{2}$ One which has caused urgent threat to life, created global conditions of deep uncertainty, and requires resilient response from healthcare systems and the organisations within them. ${ }^{3}$ However, while hierarchical decision-making and tight control is important for efficient functioning in routine conditions, ${ }^{8}$ these become inappropriate in the novel conditions currently being faced. ${ }^{27}$ Therefore, contrary to the instinctive reaction to tighten control, the resilience of healthcare systems depends on the flexibility enabled by loosening control. ${ }^{5}{ }^{6}$ In these novel circumstances, maintaining existing routines and processes is likely to backfire, ${ }^{9}$ as the order they wish to maintain no longer exists. ${ }^{16}$ Instead, the construction of a new order is required, by creatively utilising existing resources, structures and processes, and enabling their recombination. ${ }^{9}$ Without the benefit of time, preparation is superseded by improvisation. ${ }^{15}$ By increasing autonomy, maintaining structure and creating a shared understanding of the situation, clinical leaders are able to increase their organisation's capacity for improvisation. When these three factors are embraced, as they were within Christchurch Hospital's response to a major earthquake, an organisation is able to respond rapidly and flexibly to the new environment, remaining resilient despite the challenges.

Acknowledgements The author would like to thank Amit Nigam for motivating him to write this paper, the helpful comments of the anonymous reviewers, as well as the quick, proactive work of the editorial team for making this paper become a reality so quickly.

Contributors ML-S is the sole author and contributor of this submission.

Funding The authors have not declared a specific grant for this research from any funding agency in the public, commercial or not-for-profit sectors.

Competing interests None declared.

Patient consent for publication Not required.

Provenance and peer review Not commissioned; externally peer reviewed.

This article is made freely available for use in accordance with BMJ's website terms and conditions for the duration of the covid-19 pandemic or until otherwise determined by BMJ. You may use, download and print the article for any lawful, non-commercial purpose (including text and data mining) provided that all copyright notices and trade marks are retained.

\section{ORCID iD}

McKenzie Lloyd-Smith http://orcid.org/0000-0002-9907-9390

\section{REFERENCES}

1 Center for Systems Science and Engineering at Johns Hopkins University. Interactive dashboard of global COVID-19 cases, 2020. Available: https://arcg.is/OfHmTX [Accessed 10 Apr 2020].

2 Boin A, Comfort LK, Demchak CC. The Rise of Resilience. In: Comfort LK, Boin A, Demchak CC, eds. Designing resilience: preparing for extreme events. Pittsburgh, PA: University of Pittsburgh Press, 2010: 1-12.

3 Williams TA, Gruber DA, Sutcliffe KM, et al. Organizational response to adversity: fusing crisis management and resilience research streams. Acad Manag Ann 2017:11:733-69.

4 Drabek TE. Predicting disaster response effectiveness. Int J Mass Emerg Disasters 2005;23:49-72

5 Boin A, 't Hart P, 't Hart P. Organising for effective emergency management: lessons from Research1. Aust J Public Adm 2010;69:357-71.

6 Neal DM, Phillips BD. Effective emergency management: reconsidering the bureaucratic approach. Disasters 1995;19:327-37.

7 Cunha MP, Cunha JV, Kamoche K. Organizational Improvisation: What, When, How and Why. In: Kamoche K, Cunha MP, Cunha JV, eds. Organizational Improvisation. Abingdon, UK: Taylor \& Francis Ltd, 2001: 93-133.

8 Bigley GA, Roberts KH. The incident command system: High-reliability organizing for complex and volatile task environments. Acad Manag J 2001;44:1281-99.
9 Sutcliffe KM, Vogus TJ. Organizing for Resilience. In: Cameron KS, Dutton JE, Quinn RE, eds. Positive organizational scholarship. San Francisco, CA: Berrett-Koehler Publishers, 2003: 94-110.

10 Faraj S, Xiao Y. Coordination in Fast-Response organizations. Manage SCi 2006;52:1155-69.

11 Kamoche K, Cunha MP, Cunha JV. Organizational Improvisation. Abingdon, UK: Taylor \& Francis Ltd, 2001

12 Rerup C. 'Houston We Have a Problem': Anticipation and Improvisation as Sources of Organizational Resilience. Comport Organ e Gestão 2001;7:27-44.

13 March JG. The Technology of Foolishness. In: March JG, Olsen JP, eds. Ambiquity and choice in organizations. Bergen, Norway: Universitetsforlaget, 1976: 69-81.

14 Roux-Dufort C, Vidaillet B. The difficulties of Improvising in a crisis situation: a case study. Int Stud Manag Organ 2003;33:86-115.

15 Crossan M, Sorrenti M. Making Sense of Improvisation. In: Kamoche K, Cunha MP, Cunha JV, eds. Organizational Improvisation. Abingdon, UK: Taylor \& Francis Ltd, 2001: 27-48.

16 Weick KE. The collapse of Sensemaking in organizations: the Mann Gulch disaster. Adm Sci Q 1993;38:628.

17 Weick KE, Sutcliffe KM. Managing the unexpected: sustained performance in a complex world. 3rd Editio. San Francisco, CA: Jossey-Bass, 2001.

18 Zhuravsky L. When disaster strikes: Sustained resilience performance in an acute clinical setting. In: Hollnagel E, Braithwaite J, Wears RL, eds. Delivering resilient health care. Milton: Routledge, 2018: 199-219.

19 Jacques CC, McIntosh J, Giovinazzi S, et al. Resilience of the Canterbury hospital system to the 2011 Christchurch earthquake. Earthquake Spectra 2014;30:533-54.

20 Dolan B, Esson A, Grainger PP, et al. Earthquake disaster response in Christchurch, New Zealand. J Emerg Nurs 2011;37:506-9.

21 Klein KJ, Ziegert JC, Knight AP, et al. Dynamic delegation: shared, hierarchical, and Deindividualized leadership in extreme action teams. Adm Sci Q 2006;51:590-621.

22 Ardagh MW, Richardson SK, Robinson V, et al. The initial health-system response to the earthquake in Christchurch, New Zealand, in February, 2011. Lancet 2012;379:2109-15.

23 Alter S. Theory of Workarounds. CAIS 2014;34:1041-66.

24 Braithwaite J, Wears RL, Hollnagel E. Resilient health care: turning patient safety on its head. Int J Qual Health Care 2015;27:418-20.

25 Debono D, Braithwaite J. Workarounds in nursing practice in acute care: A case of a health care arms race? In: Resilient health care, volume 2: the resilience of everyday clinical work, 2017: 23-38.

26 Weick KE. Introductory Essay_-Improvisation as a Mindset for organizational analysis. Organ Sci 1998:9:543-55.

27 Weick KE, Sutcliffe KM. Managing the unexpected: resilient performance in an age of uncertainty. 2nd Edn. San Fransico, CA: Jossey-Bass, 2007.

28 Bye RJ, Almklov P, Antonsen S, et al. The institutional context of crisis. A study of the police response during the 22 July terror attacks in Norway. Saf Sci 2019;111:67-79.

29 Roberts KH. Managing high reliability organizations. Calif Manage Rev 1990;32:101-13.

30 Weick KE, Sutcliffe KM, Obstfeld D. Organizing for High Reliability: Process of Collective Mindfulness. In: Sutton RI, Staw BM, eds. Research in organizational behavior. Stanford: Jai Press, 1999: 81-123.

31 Roberts KH, Bea R. Must accidents happen? lessons from high-reliability organizations. Acad Manag Perspect 2001;15:70-8.

32 Brandon S. Loma Linda University Children's Hospital receives 2019 Leapfrog Top Hospital Award, 2019. Available: https://news.llu.edu/patient-care/loma-lindauniversity-childrens-hospital-receives-2019-leapfrog-top-hospital-award\#_fwcall [Accessed 9 Apr 2020].

33 Kamoche K, Cunha MPe. Minimal structures: from jazz Improvisation to product innovation. Organ Stud 2001;22:733-64.

34 Kreps GA, Bosworth SL, Disaster BSL. Disaster, organizing, and role enactment: a structural approach. Am J Sociol 1993:99:428-63.

35 Bechky BA, Okhuysen GA. Expecting the unexpected? how SWAT officers and film crews handle surprises. Acad Manage J 2011;54:239-61.

36 Rimstad R, Sollid SJM. A retrospective observational study of medical incident command and decision-making in the 2011 Oslo bombing. Int J Emerg Med 2015:8:1-10.

37 Okhuysen GA, Bechky BA. 10 Coordination in Organizations: An Integrative Perspective. Acad Manag Ann 2009:3:463-502.

38 Hoffer Gittell J, Gittell JH. Coordinating mechanisms in care provider groups: relationa coordination as a mediator and input uncertainty as a Moderator of performance effects. Manage Sci 2002;48:1408-26.

39 Schakel JK, Wolbers J. To the edge and beyond: how fast-response organizations adapt in rapidly changing crisis situations. Human Relations 2019:4:001872671989345.

40 Vera D, Crossan M. Theatrical Improvisation: lessons for organizations. Organ Stud 2004:25:727-49. 